\title{
O ESTADO DA ARTE SOBRE A FORMAÇÃO DE PESQUISADORES NO ESPAÇO GRUPAL
}

\author{
Denize da Silveira Foletto ${ }^{1}$
}

Silvia Maria de Aguiar Isaia ${ }^{2}$

\section{Resumo}

Este artigo apresenta um mapeamento de produções científicas brasileiras e estrangeiras sobre a temática formação de pesquisadores no espaço grupal. Faz parte de uma pesquisa realizada em uma universidade federal do interior do RS, Brasil. A metodologia possui afinidades com a pesquisa qualitativa, de tipo Estado da Arte, sugerindo um mapeamento temático. Foram analisados trabalhos das reuniões da ANPED nacional e dos encontros do ENDIPE, bem como dissertações e teses do contexto da RIES - Rede Sulbrasileira de Investigadores de Educação Superior e trabalhos do portal de Periódicos CAPES/MEC, na base de dados Web of Science. Com base na Análise do Conteúdo (BARDIN, 1977), foi possível agrupar categorias temáticas referenciais que são comumente discutidas nos trabalhos analisados: Concepção de grupo, Formação de pesquisadores e Relação entre docência e pesquisa. Com este trabalho percebeu-se a necessidade de se explorar ainda mais a temática da formação de pesquisadores, em especial no contexto grupal, evidenciando quais fatores colaboram para que os sujeitos desenvolvam a capacidade de tornarem-se pesquisadores multiplicadores e competentes.

Palavras-chave: Formação de pesquisadores; Estado da arte; Docência superior

\section{STATE OF ART ON THE RESEARCHERS' FORMATION IN GROUP SPACE}

\footnotetext{
${ }^{1}$ Doutoranda do Programa de Pós-Graduação em Educação, (UFSM/RS). Professora Estadual do RS. Endereço: E-mail: denizefoletto@gmail.com

${ }^{2}$ Doutora em Educação pela Universidade Federal do Rio Grande do Sul (UFRGS). Professora do Programa de Pós-Graduação em Educação da UFSM, na Linha de Pesquisa Formação, Saberes e Desenvolvimento Profissional e Professora Adjunta do Centro Universitário Franciscano (UNIFRA). Líder do Grupo de Pesquisa Trajetórias de Formação (GTFORMA/CNPq). Pesquisadora Sênior CNPq. E-mail: silviamariaisaia@gmail.com
} 


\begin{abstract}
This paper presents a mapping of brazilian and foreign scientific productions about the formation of researchers in the group space. It is part of a survey conducted at a federal university in the countryside of RS, Brazil. The present methodology possesses affinities with a qualitative research, such as State of the Art, suggesting a thematic mapping. We analyzed the work of the ANPED and ENDIPE meetings, as well as dissertations and theses from the context of RIES - Rede Sulbrasileira de Investigadores de Educação Superior and works of CAPES/MEC Periodical portal, in the Web of Science database. Based on the Content Analysis (BARDIN, 1977), it was possible to group reference thematic categories that are commonly discussed in the analyzed works: Group conception, Researchers' formation and Relationship between teaching and research. With this work, it was possible to understand the need to explore the issue of the researchers' formation, especially in the group context, showing which factors contribute to the ability of the subjects to become multiplier and competent researchers.
\end{abstract}

Keywords: Research formation; State of art; Higher education teaching

\title{
SITUACIÓN ACTUAL DE LA FORMACIÓN DE INVESTIGADORES EN ESPACIO DE GRUPO
}

\section{Resumen}

Este artículo presenta un mapeo de producciones científicas brasileñas y extranjeras sobre la temática formación de investigadores en el espacio del grupo. Es parte de una investigación realizada en una universidad federal del interior del RS, Brasil. La metodología posee afinidades con la investigación cualitativa, de tipo Estado del Arte, sugiriendo un mapeamiento temático. Se analizaron trabajos de las reuniones de la ANPED nacional y de los encuentros del ENDIPE, así como disertaciones y tesis del contexto de la RIES - Red Sulbrasileña de Investigadores de Educación Superior y trabajos del portal de Periódicos CAPES/MEC, en la base de datos Web of Science. Con base en el Análisis del Contenido (BARDIN, 1977), fue posible agrupar categorías temáticas referenciales que son comúnmente 
discutidas en los trabajos analizados: Concepción del grupo, Formación de investigadores y la Relación entre la enseñanza y la investigación. En este trabajo, se percibió la necesidad de explorar cada vez más la formación de investigadores, en particular en el contexto de grupo, evidenciando cuáles factores han contribuido para que los sujetos desarrollen su capacidad de convertirse en investigadores multiplicadores y competentes.

Palabras clave: Formación de investigadores, Estado del arte; Enseñanza superior

\section{INTRODUÇÃO}

Este $\operatorname{artigo}^{3}$ apresenta um levantamento de produções científicas brasileiras e estrangeiras sobre a temática formação de pesquisadores no espaço grupal. A ideia de investigar a temática da formação de pesquisadores no espaço grupal surgiu no imo de um grupo de pesquisa consolidado no $\mathrm{CNPq}$, de uma universidade federal do interior do Rio Grande do Sul, a partir da proposta de análise dos dados no contexto grupal. Para tanto, um grupo de pesquisadoras ${ }^{4}$ esteve engajado em pensar, aprender e interpretar as narrativas das entrevistas com 60 professores universitários de diferentes áreas de conhecimento. Assim, a tese da qual este artigo faz parte discute a formação de pesquisadores no espaço grupal, sendo, portanto, necessária à investigação, a discussão de estudos já realizados na área da pesquisa.

O mapeamento temático proposto se deu no sentido de identificar, conhecer e analisar estudos sobre a temática da pesquisa, a fim de propor, a partir de outros estudos, um trabalho original no processo de produção do conhecimento na área da educação.

Nesse sentido, buscamos refletir, através da construção do Estado da Arte, sobre até que ponto a pesquisa que estamos realizando é efetivamente uma contribuição ao tema a que se destina. Para tanto, foram analisadas, com base na Análise do Conteúdo (AC) (BARDIN, 1977), categorias temáticas que emergiram de produções científicas brasileiras e estrangeiras sobre a formação de pesquisadores no espaço grupal. Para Laurence Bardin, escolhida neste artigo como referencial devido à ampla utilização desta autora em diferentes pesquisas, a AC é

um conjunto de técnicas de análise das comunicações visando obter, por procedimentos, sistemáticos e objetivos de descrição do conteúdo das mensagens, indicadores (quantitativos ou não) que permitam a inferência de conhecimentos

\footnotetext{
${ }^{3}$ Constitui-se em uma pesquisa de doutorado realizada em uma universidade federal do interior do Rio Grande do Sul, RS, Brasil.

${ }^{4}$ Dentre os 17 membros do grupo, todos são do sexo feminino.
} 
relativos às condições de produção/recepção [...] destas mensagens. (BARDIN, 1977 p. 42).

Dessa forma, entendemos que o texto na AC é uma forma de manifestação do sujeito pesquisador. Ou seja, por meio de unidades de texto (palavras, frases ou características) recorrentes, que se repetem com frequência, o pesquisador as categoriza, fazendo emergir expressões que representem a temática pesquisada. Neste trabalho de análise é preciso identificar os elementos comuns no texto de maneira que seja possível agrupá-los. Portanto, a análise categorial pode ser temática, ou seja, é possível construir categorias conforme os temas que emergem do texto.

Assim, entendemos o Estado da Arte como um processo contínuo e importante, pois considera os estudos já realizados como contribuições para uma nova produção. Nesse sentido, embasados em Romanowski e Ens (2006), buscamos compreender o modo como poderíamos realizar um levantamento de produções em determinados campos que servisse ao que nos propomos e, consultando Romanowski (2002), encontramos procedimentos que ajudaram no desenvolvimento do trabalho: a) Definição dos descritores (palavras-chave); b) Localização dos bancos de pesquisas; c) Estabelecimento de critérios para a seleção do material; d) Levantamento de teses e dissertações catalogadas e artigos publicados em revistas; e) Coleta do material de pesquisa disponibilizados eletronicamente; f) Leitura das publicações com elaboração de síntese preliminar, considerando o tema, os objetivos, as problemáticas, metodologias, conclusões e a relação entre o pesquisador e a área; g) Organização do relatório do estudo compondo a sistematização das sínteses, identificando as tendências dos temas abordados e as relações indicadas nos artigos, teses e dissertações; $h$ ) Análise e elaboração das conclusões preliminares.

Desse modo, esses estudos nos possibilitaram fazer um balanço efetivo da nossa pesquisa como contribuição na constituição do campo teórico, permitindo delimitar a envergadura da nossa pesquisa, comprovando a originalidade da temática e os possíveis encaminhamentos para o desenvolvimento da proposta.

\section{DESENVOLVIMENTO DO TRABALHO}

Em um primeiro momento, o estudo realizou uma busca em sete repositórios. Dentre esses, três grandes eventos com reconhecimento nacional da área da educação e teses e dissertações referentes a quatro universidades do Rio Grande do Sul. Desta forma, 
delimitamos a busca pelos trabalhos publicados no período de 2008 a 2013, uma vez que a pesquisa de doutoramento teve início no ano de 2013.

Os repositórios envolvidos foram quatro universidades brasileiras que fazem parte da RIES (Rede Sulbrasileira de Investigadores de Educação Superior), tendo em vista que a RIES tem se constituído como uma rede ímpar no que se refere à Educação Superior em nosso país. São elas: Universidade Federal de Santa Maria/UFSM, Universidade Federal do Rio Grande do Sul/UFRGS, Pontifícia Universidade Católica do Rio Grande do Sul/PUCRS e Universidade Federal de Pelotas/UFPel. As demais fontes pesquisadas foram os eventos (também brasileiros) da Associação Nacional de Pós-Graduação e Pesquisa em Educação (ANPED), o Seminário de Pesquisa em Educação da Região Sul - Reunião Científica Regional (ANPED SUL) e as produções apresentadas nos eventos do Encontro Nacional de Didática e Prática de Ensino (ENDIPE). A escolha por estes eventos se deu pela importância dos mesmos no campo da educação, pois são nesses eventos que são apresentadas e discutidas as pesquisas mais recentes na área. Como a ANPED SUL não é anual, e ocorre em anos intercalados, consideramos dentro do período investigado os anos de 2008, 2010 e 2012. Os Grupos de Trabalhos (GTs) pesquisados foram o GT8 (Formação de Professores) e GT11 (Política de Formação de professores). Vale destacar que os trabalhos revisitados no ENDIPE são referentes aos anos de 2008, 2010 e 2012, mesmos anos em que ocorreram a ANPED SUL.

Num segundo momento, no sentido de explorarmos ainda mais as investigações acerca das produções que poderiam estar sendo feitas sobre a temática da formação de pesquisadores no espaço grupal, fizemos uma pesquisa no Portal de Periódicos CAPES/MEC, na base de dados Web of Science, em que direcionamos nossas buscas apenas para o descritor "Researchers' Formation" (Formação de pesquisadores) com o intuito de coletar material comum ao tema em outros países e também porque esse é o campo primordial no contexto da pesquisa.

Ressaltamos que foram encontrados alguns trabalhos semelhantes a esse que nos propomos. Contudo, com vieses, temáticas e interesses diferentes dos nossos. Assim, é certo que nos utilizamos dessas diferentes análises para formar a nossa, de maneira que fizesse sentido para a nossa pesquisa. A investigação ocorreu nos eventos mencionados e a busca dos trabalhos tomou como base os seguintes descritores: 1) Docência Superior; 2) Grupo de Pesquisa; 3) Análise Narrativa Grupal; 5) Formação de Pesquisadores. 
A busca nos eventos foi realizada pela leitura dos títulos, resumos e posteriormente, trabalhos completos, em vista de que os mesmos estão disponibilizados eletronicamente (sites e CDs). Em seguida, procuramos teses e dissertações disponíveis na Biblioteca Digital de Teses e Dissertações (BDTD) com a intenção de encontrarmos trabalhos ligados às Universidades escolhidas. A busca foi realizada com base nas mesmas palavras-chave utilizadas para a pesquisa nos eventos mencionados antes. Após a classificação das dissertações e teses pelos títulos, o segundo passo foi realizarmos a leitura dos resumos para vislumbrarmos se o trabalho realmente correspondia com a temática pretendida. À medida que a pesquisa avançava, encontrávamos algumas dificuldades como, por exemplo, resumos que não condiziam com o título apresentado, resumos com poucas informações, tornando necessário o aprofundamento na leitura de todos os trabalhos, demandando tempo. Desse modo, mesmo considerando a possibilidade de uma margem de falhas nos resultados das buscas, pois a pesquisa depende da confiabilidade do sistema de filtros dos repositórios digitais, foi possível percebermos a quase inexistência de trabalhos referentes à temática da nossa pesquisa.

Por último, e para finalizar as buscas, no banco de dados Web of Science, direcionamos a demanda para o descritor "Researchers' Formation” (Formação de pesquisadores), estipulando o tempo nos últimos 05 anos, ou seja, de 2010 a 2015. Encontramos 2.337 trabalhos. Então, refinamos a pesquisa como Tipo de Documento: Article; Área de pesquisa: Education Educational Research; e Idioma: English. Emergiram 48 artigos publicados em revista e como resultados dessa triagem, foram classificados, como pesquisa relacionada ao tema, 07 artigos. Realizando uma análise segmentada para o foco deste estudo, identificamos 03 trabalhos que se aproximavam da temática. Assim, mesmo considerando a possibilidade de uma margem de falhas nos resultados das buscas, foi possível encontrar referenciais significativos para a constituição de nosso estudo.

Como resultado das buscas, percebemos a quase inexistência de trabalhos que considerem o enfoque ou trabalhem com o tema formação de pesquisadores no espaço grupal. Este fato nos causa preocupação, no sentido que, ao mesmo tempo em que evidenciamos indicativos de que se existe a preocupação pelos pesquisadores com a formação de pesquisadores (o que também não foi um dado significativo), desconsideram essa formação no espaço grupal. Desse modo, entenderemos a importância da formação de pesquisadores no espaço grupal, à medida que tivermos claro que a contribuição neste sentido, está na 
capacidade de reflexão conjunta e na compreensão crítica do processo de investigação por parte dos sujeitos.

\section{DISCUSSÃO DAS PRODUÇÕES}

Como descrito anteriormente, poucos estudos exploram a temática da formação de pesquisadores no contexto grupal, foco do nosso interesse e por isso, centramos principalmente nessa literatura. As buscas identificaram sete estudos (OLIVEIRA, 2011; PIVETTA, 2011; SCOLA, 2012; ROSSETTO, 2013; RYSER; MARKEY, HALSETH 2013; SINCLAIR; BARNACLE, CUTHBERT, 2013; KYEI-BLANKSON, 2014) que foram classificados como pesquisas relacionadas ao tema.

Mais do que uma revisão compreensiva e sistemática, o que segue promove uma visão geral sobre aspectos importantes da temática, que foram sustentados e movidos pelo desafio de conhecer e trabalhar a partir do já produzido, para depois, construir o que ainda não foi feito. Este trabalho permite que reconheçamos a possibilidade de uma aprendizagem evolutiva na área da formação de pesquisadores no contexto grupal.

Assim, após a seleção dos trabalhos citados antes, fizemos a leitura dos mesmos de maneira que pudéssemos identificar elementos convergentes e divergentes entre eles, tentando explorar a crítica das diferentes perspectivas e os pontos onde os autores se alinham e diferem significativamente, de modo que tais "mapeamentos" sugerissem possibilidades interessantes para a temática da pesquisa. A partir disso, foi possível agrupar categorias temáticas referenciais que são comumente discutidas nos trabalhos analisados: Concepção de grupo; Formação de Pesquisadores; e Relação entre docência e pesquisa.

\subsection{Concepção de grupo}

Sobre esta categoria, destacamos que a concepção presente sobre grupos nos textos estudados (OLIVEIRA, 2011; PIVETTA, 2011; SCOLA, 2012) se caracteriza pelo entendimento de que o mesmo pode ser um dispositivo de aprendizagem e formação docente. Mesmo usando palavras e expressões diferentes, podemos perceber que as três autoras coadunam do mesmo entendimento no que se refere ao conceito de grupo, uma vez que, Oliveira (2011, p. 181) compreende que "[...] grupos se constituem por pessoas que compartilham um objetivo comum e, por isso, estão ligadas entre si”. Scola (2012) entende 
grupos como um conjunto de pessoas interligadas entre si em interações contínuas constituindo uma unidade que modifica suas características ao longo do tempo, desenvolvendo comportamentos de forma interdependentes durante o tempo que o grupo existir. Já Pivetta (2011) parafraseia as palavras de Souto (2007, p.18) para dizer que grupo “consiste na reunião de pessoas com objetivos comuns que caminham num processo compartilhado, que engloba o individual, o coletivo e o institucional, num campo de interconexões do histórico, do social e do cultural". Assim, a partir do pensamento das autoras, inferimos que grupos se compõem por pessoas integradas que compartilham de um objetivo em comum, que se relacionam entre si e que se modificam ao longo do tempo, de acordo com suas características e proposições.

Sobre este ponto, em consonância com a temática que nos propomos estudar e, com base no estudo realizado pelas integrantes do grupo de pesquisa, de autores considerados precursores da dinâmica grupal (LEWIN, 1948; PICHON-RIVIÈRE, 1994; SOUTO, 2007), acrescentamos que nosso entendimento acerca do que é um grupo parte da compreensão de que são pessoas reunidas com um objetivo comum e que, mesmo com dificuldades e limitações, trabalham de acordo com o seu tempo envolto no desafio de aprender, ensinar, criar, transformar e motivar, procurando sempre chegar a um entendimento neste espaço coletivo.

Neste movimento, enquanto Pivetta (2011) discute sobre a formação do docente do ensino superior, Oliveira (2011) reflete sobre a formação a partir de um outro lugar que é o grupo. O enfoque do trabalho de Pivetta é a reflexão sobre a ação docente no grupal, ao passo que o enfoque de Oliveira é estudar o grupo de pesquisa no espaço coletivo. Contudo, mesmo com posições diferentes, ambas veem o grupo como dispositivo. Pivetta vê o grupo reflexivo como um dispositivo de aprendizagem docente "na medida em que se estabelece o encontro e institui a reflexão dos professores sobre si e sobre sua prática socialmente construída e [re]significada, tendo como premissa a possibilidade de mudança, transformação e aprendizagem" (PIVETTA, 2014, p.114) à medida que Oliveira (2011, p. 181) define dispositivo como uma ferramenta e o entende como "qualquer lugar/espaço no qual se constitui ou se transforma a experiência de si, um movimento em que o sujeito está implicado". Essa implicação pode acontecer consigo mesmo, a partir dos outros e com os outros.

Um diferencial que encontramos nos trabalho de Oliveira é que a autora traz acréscimos significativos na questão do dispositivo. Um refere-se à 
inscrição da pessoa no lugar formativo como alguém que se coloca, experimenta-se, não participa passivamente, ouvindo teorizações sobre experiências produzidas pelos outros, mas (re)visita seus repertórios formativos, problematizando-os também na escuta do outro. (OLIVEIRA, 2011, p. 181).

Ainda, diz que o dispositivo quando se assenta no espaço e no lugar do grupo a pesquisa-formação-autoformação, produz nas pessoas processos que movimentam com "potencialidades inesperadas". Este dado é relevante já que a soma dessas ideias tem um efeito positivo na conceituação de dispositivo e nos ajuda a compreender essa fala, no seu sentido mais amplo, que o sujeito precisa além de colocar-se ativo de/na sua vida, necessita colocar-se na perspectiva e na escuta do outro, oportunizando a si mesmo a reflexão e, consequentemente, a produção de uma mudança (talvez inesperada) na formação e um crescimento pessoal e profissional.

A importância de como o grupo se constituiu como dispositivo, seja de aprendizagem docente, seja de formação, também foi identificada nesses estudos. Na tese analisada, Pivetta (2011) revela onde o grupo começou a se constituir. Assegura que foi a partir da narrativa geradora do pensamento reflexivo dos professores, no qual aconteceu e se manteve a partir das vivências e experiências, pois quando há reflexão sobre um problema, inicia-se um movimento, em que a reflexão de um professor gera a reflexão dos demais. No texto de Oliveira (2011, p. 182), a autora reforça essa ideia ao afirmar que "a possibilidade de pensar sobre o instituído, da reflexão e da crítica é também a perspectiva de alterar o que está feito". Assim, Pivetta entende que o grupo reflexivo constitui-se em dispositivo que contribui para a aprendizagem docente,

à medida que a reflexão grupal sobre o cotidiano do professor, a interação com os sujeitos e com o meio [re]significam a docência superior. Porém, a constituição grupal exige conhecimentos e habilidades próprias ao campo teórico conceitual envolvido, e acima de tudo, a disposição e o compromisso das pessoas/professores com sua formação. Esta implica um permanente processo de aprendizagem. (PIVETTA, 2014, p. 128).

Em linha convergente, Oliveira (2011) também nos remete à ideia de que o sentido de estarmos junto no grupo é de conhecer como nos tornamos o que somos. Por isso, a formação, no cenário grupal, assume uma relação temporal no momento em que mexe com as lembranças, imagens passadas e que são reconstruídas no presente. Através das narrativas podemos conhecer a produção e os deslocamentos de sentido. A memória, segundo a autora, é a mola propulsora para tecer as vivências, de criar novas subjetividades e perspectivas de 
formação. Nesse contexto, traz como dispositivo de formação as experiências vividas dentro do grupo.

Nesse sentido, concordamos com Ferry (2004) quando nos diz que a formação é diferente de ensino e aprendizagem, ou seja, o ensino e a aprendizagem são suportes da formação, e não constituem a formação em si. Dessa forma, vemos dispositivo de aprendizagem e dispositivo de formação, imbricados, pois a aprendizagem está fundida ao fenômeno complexo da formação. A aprendizagem é um dos fatores fundamentais da formação, contudo a formação não se reduz ao processo de aprendizagem simplesmente. Nestes termos, inferimos que a formação "puxa" a aprendizagem para uma dimensão que não se reduz somente à memória, ao perceptivo ou ao intelectual, como é comum encontrarmos nos cenários educacionais. Aqui evidenciamos e constatamos que se trata de uma aprendizagem que forma e que aconteceu de fato a partir do grupal.

Dando continuidade à reflexão, evidenciamos o pensamento de Scolla (2012), em que a autora traz a ampliação do estudo a partir da Teoria da Complexidade de Morin, explicando cada princípio (dialógico, retroativo, recursivo e reintrodução do conhecedor no conhecimento), passando a compreender o grupo pesquisado como um sistema complexo, pois contemplou e concretizou a ideia de abertura e fechamento. Como a intenção desse trabalho era compreender como ocorreu o processo no grupo de formação de coordenadores, o foco foi verificar o grupo como totalidade, por isso, considerou que o processo grupal seria clarificado sob a ótica do discurso coletivo e não do individual.

Assim como as outras autoras supracitadas, o trabalho de Scolla (2012) valorizou as vivências, ou seja, atividades experienciais como feedback interpessoal, relatórios sobre sentimentos e percepções, que proporcionaram a vivência no processo grupal e, como consequência, o vivenciado no grupo resultou no aprendizado. As intervenções facilitaram o aprendizado do grupo a respeito de si, como também consolidaram aspectos teóricos sobre grupos. Desse modo, o aprendizado precisa ser posto em ação para ter sentido. De acordo com a autora, "termos como confiança, intimidade e afetividade geram aprendizado [...] e o grupo tornou-se campo de aprendizagem" (SCOLLA, 2012, p. 20).

Outra característica importante que apareceu em dois trabalhos (OLIVEIRA, 2011; SCOLLA, 2012) foi a diversidade em relação à área de formação dos integrantes dos grupos. Ambas contemplam a multiplicidade que constitui os grupos, como um fator positivo, pois os atores falam a partir de suas variadas perspectivas. O que difere do grupo reflexivo de Pivetta (2011), que trabalhou com professores da mesma área. 
Um dado inesperado do estudo de Scolla (2012) diz respeito ao levantamento da definição de processo. Ao comentar sobre isso, a autora diz que vários são os estudiosos que trabalham sobre o tema grupos, porém pouco se encontra a respeito do que entendem por processo grupal, mesmo com um livro intitulado Processo Grupal, como é o caso de PichonRivière (2009), que coloca como o "acontecer grupal". Reportando-nos novamente aos dois outros textos analisados aqui, confirmamos o que Scolla aborda, pois Pivetta (2014, p. 122) não define processo, mas sim, trata como acontecer grupal em que o mesmo vai se estabelecendo pelo "conjunto de docentes envolvidos nas suas chegadas e despedidas, tendo em vista a incorporação de novos membros no grupo, bem como o afastamento de outros professores que se arredam da instituição". Do mesmo modo, Oliveira (2011) não define processo, mas traz o espaço grupal como um lugar aprendente, em que favorece a construção de um imaginário instituinte. Nesse ponto, Scolla (2012) transcende ao definir processo grupal em seu estudo, uma vez que é necessário definir a quais grupos referem, pois fica a ideia que um fenômeno seja universal e acontece com todos os grupos. Podem até ser universais, porém, também podem ser contextuais, ocorrendo em situações diferentes nos grupos. Assim, consideram a verdade relativa e não absoluta. Pensando nisso, a autora define processo grupal como algo que se refere "as relações que os participantes desenvolvem entre si, bem como a vivência dos fenômenos grupais que ocorrem recursivamente durante a vida do grupo" (SCOLLA, 2012, p. 20-21).

Por fim, todos os trabalhos acima são unânimes ao destacar a intenção da teoria como colaboração para futuras pesquisas. Porém, Oliveira (2011) vai além, ao sinalizar que olhar a formação sob a perspectiva grupal constitui-se como uma nova temática dentro da universidade, pois nem sempre esses dispositivos são valorizados. Sob esses aspectos, pretendemos com a nossa pesquisa, dar continuidade aos estudos já realizados, porém expandindo a pesquisa para a formação de pesquisadores no contexto grupal, já que existem muitos grupos no meio acadêmico com fins de pesquisa, mas que muitas vezes, não atendem ao real objetivo que é formar pesquisadores.

\subsection{Formação de pesquisadores}

Para discutirmos esta categoria decidimos pelos trabalhos de Ryser, Markey e Halseth (2013) e Sinclair, Barnacle e Cuthbert (2013), pois foram os textos que mais se relacionaram com este assunto. 
Enquanto os autores Sinclair, Barnacle e Cuthbert (2013) discutem como o doutorado contribui para a formação de pesquisadores ativos, Ryser, Markey eHalseth (2013) discorrem sobre o desenvolvimento da próxima geração de pesquisadores de base comunitária, indicando alguns passos que os universitários devem percorrer. Consideramos esses achados de suma importância para o nosso estudo, pois eles além de contribuir significativamente com a literatura, reforçam a ideia de que se faz necessário desenvolver o tema sobre a formação de pesquisadores mais profundamente.

Na primeira produção analisada, os autores (SINCLAIR; BARNACLE; CUTHBERT, 2013) discutem os fatores que facilitam a formação de um pesquisador ativo. Segundo eles, essa questão é relativamente recente e citam o estudo de Gardner (2008) para fortalecer e embasar a pesquisa deles. Os autores dizem que o estudo de Gardner (2008) se baseou em entrevistas com 40 candidatos a doutoramento em duas instituições americanas, através de uma gama de disciplinas, e analisou o processo de se tornar um pesquisador independente. $\mathrm{O}$ estudo apontou que os estudantes não foram adequadamente preparados para as múltiplas transições requeridas para tornarem-se pesquisadores independentes. Descobriu ainda que a participação dos alunos da área das ciências em grupos pares nos laboratórios é mais apta a torná-los independentes comparado ao trabalho isolado desenvolvido pelos alunos da área das humanas. Em outras palavras, é mais significante, para estabelecer um sentido e eficácia de pesquisa, quando os estudantes trabalham juntos, pois neste encontro, há a possibilidade de discussão e troca de ideias. Sendo assim, entendemos que a aquisição da independência através da escolha de "tornar-se par" pode ser crucial para a formação de pesquisador ativo.

Assim, os autores trazem, como um fator além, a habilidade dos alunos de perguntar e fornecer ajuda a outros como um indicador de capacidade colaborativa como é requerido em muitos campos. Para Sinclair, Barnacle e Cuthbert (2013), esta descoberta também desafia a noção valorizada do pesquisador "independente". Correlacionando as ideias dos autores com a temática da nossa pesquisa sobre a formação de pesquisadores no contexto grupal, fomentamos a ideia de que o espaço grupal pode favorecer a formação de pesquisadores ativos, uma vez que aprendem a trabalhar de modo colaborativo como parte de um grupo que compartilha altos níveis de comprometimento, motivação e concepções comuns do propósito da pesquisa, angariando conhecimento e aprendizado.

No outro texto analisado, os autores Ryser; Markey; Halseth (2013) identificam alguns dos modos por meio dos quais podem fazer um trabalho melhor ao apresentar os estudantes de graduação ao campo da pesquisa de base comunitária, como por exemplo: compartilhar 
informação e conhecimento sobre como encontrar e financiar oportunidades de pesquisa; fornecer orientação sobre como os estudantes podem obter o melhor das experiências de pesquisa; e proporcionar conhecimento sobre como efetivamente os alunos podem se comprometer com parceiros comunitários. Estas lições, segundo os autores, buscaram colocar os estudantes de graduação em uma melhor posição para que se engajem como líderes pensantes, colaboradores ou participantes das iniciativas de pesquisa de base comunitária.

No contexto dessas demandas, os autores nos dizem que os estudantes têm hoje muitas opções disponíveis para encontrar oportunidades para a pesquisa, tornando-os os melhores dentro do curso deles ou do trabalho de pesquisa. Muitos cursos universitários, tanto em níveis iniciais como finais, oferecem projetos de aula, bem como monografias para que os estudantes possam conduzir seus estudos rumo à investigação.

Outro tópico que os autores abordaram foi sobre como os estudantes podem tirar melhor proveito das experiências de pesquisa deles. Este tópico é diretamente relevante à medida que inclui os grupos de pesquisas como grandes aliados para o crescimento do estudante. Este fator é consistente com aquele de Sinclair, Barnacle e Cuthbert (2013), pois os achados desses autores sugerem que a formação de um pesquisador ativo, pode partir da formação dos acadêmicos quando são estimulados a desempenhar um papel de pesquisador dentro do próprio grupo de pesquisa. Este fator reforça a intenção de nossa pesquisa, quando nos propomos a formar pesquisadores no espaço grupal e que, neste caso, os integrantes do grupo de pesquisa são os atores principais.

O estudo dos autores aponta, em primeiro lugar, que para obter o máximo de uma experiência de pesquisa colaborativa, os estudantes de graduação precisam otimizar o modo como eles trabalham dentro do grupo de pesquisa. Para atingir tal objetivo, a primeira e mais importante lição para os estudantes é a de fazerem suas tarefas sobre o grupo de pesquisa e o projeto. Obter uma cópia do projeto irá ajudá-los no sentido de compreenderem os propósitos e os objetivos da pesquisa. O estudo dos autores, no entanto, não explora a questão da literatura, que a nosso ver, é fundamental. Somamos a isso, que o projeto "guarda-chuva" também identificará e conterá as literaturas prévias necessárias, bem como os conceitos teóricos dos quais os estudantes precisarão estar familiarizados, para que possam participar inteiramente de todos os aspectos do processo de pesquisa.

Em segundo lugar, os autores alertam para o fato de que os estudantes precisam expandir suas oportunidades para conquistar uma boa experiência de aprendizagem. Dizem que eles podem fazer isso se dedicando a conhecer e interagir com todos os pesquisadores 
identificados no propósito do projeto. Isto deve incluir o ato de compreender o conhecimento prévio necessário de pesquisa, seus papéis e responsabilidades no projeto, bem como suas informações de contato. Ao ter um entendimento compreensivo do grupo de pesquisa, os estudantes poderão estar aptos a criar oportunidades para trabalharem com outros membros experientes do grupo ou mesmo para facilitar as trocas com outros parceiros do projeto. Talvez o mais importante seja o fato de os estudantes precisarem identificar e entender a relação entre os papéis e as responsabilidades deles e o resto do grupo como base para o bom desenvolvimento das relações de trabalho/aprendizagem e oportunidades.

Em terceiro e último lugar, os autores atentam que os estudantes precisam ter a certeza de que eles são parte do "laço" de comunicação do projeto de pesquisa, uma vez que se eles forem excluídos das informações mais importantes, poderão se sentir isolados ou perdidos durante as discussões em grupo, impactando em suas habilidades de participação nas atividades de pesquisa e no aproveitamento das oportunidades emergentes. Além disso, acrescentamos ao estudo dos autores citados neste texto, que os estudantes a fim de manterem-se conectados com a rede de comunicação do grupo de pesquisa, devem frequentar encontros, oficinas e conferências; estarem incluídos nas listas de e-mails e acessar/participar das ferramentas das mídias sociais. Embora o espaço possa ser limitado nas configurações da universidade, ter um espaço de trabalho pode ajudar os estudantes a ficarem a par das discussões formais e informais em andamento sobre a pesquisa. Acima de tudo, manter uma rotina de comunicação é chave.

Por fim, para finalizar os estudos de Ryser, Markey e Halseth (2013), eles se deram conta em sua pesquisa que deveriam fornecer conhecimento também sobre como efetivamente os estudantes podem se engajar com parceiros comunitários, e que, aqui, aproveitaremos sob forma de grupo de pesquisa.

Os autores nos dizem que uma vez que os estudantes tenham uma boa compreensão do projeto de pesquisa e o lugar onde cabem os seus papéis e responsabilidades dentro do projeto, eles precisam, propositadamente, desenvolver um plano para obter o máximo das suas experiências de pesquisa. Pensando nisso, trazem oito conjuntos-chave de habilidades que os estudantes de graduação precisam desenvolver. Estes conjuntos incluem a escrita, a comunicação, o desenvolvimento da pesquisa e a ética, a coleta de dados, a análise, as habilidades organizacionais, a administração e a gestão de projetos e o desenvolvimento das fontes humanas. Entendemos assim, que cada uma dessas habilidades pode ser expandida com uma variedade de tarefas de pesquisa. 
Ao trabalharem para tirar o máximo de proveito da experiência de pesquisa, os estudantes de graduação precisam reconhecer que as experiências de aprendizagem podem ser impactadas pela contração temporal do projeto e o nível de estudo deles. Os estudantes precisam querer se conectar cedo com os grupos de pesquisa, a fim de ganhar mais tempo e mais oportunidades para seu crescimento e desenvolvimento. Desse modo, os estudantes precisam ter iniciativa em aprender com seus professores/orientadores, pois através da interação, se tornam parte de uma comunidade de aprendizagem ativa, na qual as distintas abordagens, conhecimento, valores e as expectativas são compartilhadas (RYSER, MARKEY; HALSETH, 2013).

Postos juntos, os estudos de Ryser, Markey e Halseth (2013) e Sinclair, Barnacle e Cuthbert (2013), indicam a natureza variável da formação de pesquisadores e alguns dos fatores que podem ser relevantes nesta formação, inclusive para as gerações futuras. Eles pontuam aspectos-chave para esta formação, expectativas e concepções que podem oportunizar o progresso e o desenvolvimento do pesquisador. Embora seja preciso um estudo mais aprofundado para confirmar isso, parece que a formação de um pesquisador ativo é aquela em que os estudantes, e todos os envolvidos no processo, compartilham ideias e concepções comuns, dentro de um espaço colaborativo de aprendizagem.

\subsection{Relação entre docência e pesquisa}

A relação entre a docência e pesquisa tem merecido a atenção dos pesquisadores, pois muitos trabalhos têm apontado resultados que indicam a necessidade de maior aprofundamento e discussão sobre a formação docente para o ensino superior, e consequentemente para a formação do pesquisador. Segundo Cunha (1988), a sala de aula é um lugar privilegiado, e estudar o que nela acontece e o porquê acontece é a primeira tarefa daqueles que se encontram envolvidos com a educação e comprometidos com uma prática pedagógica competente. Em outras palavras, levar em conta as concepções e pensamentos de todos aqueles que fazem parte da prática pedagógica, pode conceder um melhor entendimento acerca da docência e sua relação com a pesquisa.

Assim, neste eixo temático, faremos a discussão da relação entre docência e pesquisa a partir, principalmente, das produções de Rossetto (2013); Sinclair, Barnacle e Cuthbert (2013) e Kyei-Blankson (2014). 
De acordo com Kyei-Blankson (2014) quando os professores são preparados como pesquisadores, eles têm maiores condições de pesquisar suas salas de aula e fazer a transposição da teoria para a prática. Entendemos assim, que o professor ao tornar-se um pesquisador, conhece os desafios, critica e trata as necessidades eficazmente, pois atinge maior abertura e torna-se ciente do que está acontecendo na sala de aula. Em meio a esses fatores, a autora declara um grande desafio a ser enfrentado pelos docentes que é a questão tempo, já que fazer pesquisa requer dos professores-pesquisadores disponibilidade de tempo e envolvimento. Este achado é consistente com o de Rossetto (2013) que em sua pesquisa, destaca o tempo de aprendizagem pessoal e tempo instituído para a pesquisa. Rossetto (2013) vê o fator tempo como uma tensão que tem como característica principal o constante conflito entre o tempo acadêmico e o tempo pessoal, e vê estes dois fatores como responsáveis pelo desequilíbrio e contradições que os estudantes possam vir a manifestar.

Concordamos com as autoras à medida que o fator tempo, neste caso, pode ser remetido a um agir estratégico, orientado pela lógica instrumental e, portanto, assumimos juntamente com as autoras, que é preciso dar apoio à investigação e oportunidades à medida que inovações vão sendo desenvolvidas na área, de modo que isso gere uma reflexão que permita uma mudança no sujeito e no espaço universitário.

A pesquisa de Kyei-Blankson (2014) descobriu que os professores na sua maioria concordam que a formação investigativa mudou seus pontos de vista como "consumidores" e produtores de pesquisa e consideram essa formação significativa para o crescimento pessoal e profissional do docente. Além disso, ressaltaram o desejo de continuar a fazer pesquisa em suas salas de aula, bem como demonstraram interesse em chamar parceiros. Ao analisarmos isso, notamos que o professor quando se engaja na pesquisa ele se torna um pesquisador reflexivo e crítico agente de mudança, pois quando olham de "fora" conseguem ver diferentes maneiras de ensinar os alunos. Esta confiança depositada no processo traz mudanças significativas na aprendizagem dos estudantes. Em relação a isso, Rossetto (2013) também contribui com a discussão. Ela cita um conjunto de elementos que considerou responsáveis na condução dos sujeitos pesquisados a experienciar a "transformação de si", que consiste nas "mudanças que a experiência da produção da pesquisa imprime no sujeito tanto no âmbito pessoal como no âmbito profissional" (ROSSETTO, 2015, p. 40). Em outras palavras, essas mudanças se constituem a partir da reflexão feita através dos fatores que levaram o sujeito ao sucesso ou aos erros no caminho da pesquisa. 
Outro dado relevante da pesquisa de Kyei-Blankson (2014) diz respeito ao professor como pesquisador em parcerias de colaboração, pois os professores sentem-se responsáveis pela condução e aplicação da pesquisa na prática, mas também fazem alusão ao desejo de formar parcerias com seus pares e com pesquisadores de outras universidades sempre que possível. Vemos esse pensamento dos professores como alguém que valoriza o compartilhamento de suas "novas habilidades", de suas investigações, tornando-se, a nosso ver, um "pesquisador multiplicador". Alinhada a este pensamento, Rossetto (2013) igualmente evidencia o trabalho grupal tanto como forma de organização da prática de pesquisa quanto como um auxílio na constituição da autonomia. A autora atenta para o fato de que a realização dos estudos no grupo permitiu modos de interação e mediação capazes de aprimorar as pesquisas tanto individuais quanto coletivas. Este é um dado instigante para a temática da nossa pesquisa, pois novamente intensifica a ideia da eficácia do trabalho coletivo ao conceituar autonomia como "uma construção particular, porém não solitária" (ROSSETTO, 2013, p. 42). Ou seja, o sujeito não constitui sua autonomia isoladamente. Pelo contrário, considera a presença do outro importante para a aprendizagem acontecer e isso não quer dizer que o sujeito precise ficar sob a dependência do outro, durante todos os momentos da produção da pesquisa e da constituição de sua autonomia nesse processo.

Outra possibilidade-chave para a formação de um pesquisador, segundo Sinclair, Barnacle e Cuthbert (2013) é a excitação, o prazer e o senso de engajamento emocional e criatividade que alguns associam com a pesquisa. Concebemos esses quesitos como algo imprescindível em relação à pesquisa, pois é preciso estabelecer um empenho imensurável com ela. O pesquisador precisa "apaixonar-se" pela pesquisa, ou seja, é essencial que exista prazer, diversão e satisfação no trabalho que está sendo realizado, de modo que se torne uma experiência transformadora de vida. Essa "paixão" é a motivação primeira para que o orientando execute a pesquisa. Parece-nos que o engajamento com o trabalho de pesquisa, aliado à criatividade, é outro aspecto primordial da formação de um pesquisador. Contudo, os autores alertam para o fato de que o link entre o engajamento emocional e criativo com o trabalho de pesquisa e a produtividade não foi investigado na vasta literatura, já que a maioria dos trabalhos focam em fatores externos e extrínsecos em vez de motivadores internos e intrísecos. Assim, atentam para a necessidade de desenvolver essas ideias mais profundamente e sugerem que essa questão pode oferecer um caminho frutífero para uma pesquisa futura. 
Por fim, baseados nos estudos, concluímos com o entendimento de que no final, o mundo da sala de aula universitária só vai mudar, quando o professor a compreender como um espaço coletivo e investigativo.

\section{CONCLUSÃO}

Neste trabalho em que nos detemos à seleção, organização, descrição e análise da produção científica referente à temática referencial da pesquisa de doutoramento, tivemos por intuito conhecer outros estudos, recolher sugestões, fazer inferências sobre os fatores que possam contribuir para a compreensão da formação de pesquisadores no espaço grupal, procurando propor algo novo no processo de produção do conhecimento.

Pudemos pontuar como mais marcante nessa análise a ideia de que um grupo se constitui a partir da narrativa geradora do pensamento reflexivo conjunto dos sujeitos, envolvendo diferentes saberes, vivências e experiências e que a formação no espaço coletivo é assumida como um lugar aprendente. Sendo assim, atentamos para o fato do quanto um trabalho coletivo de produção de conhecimentos contribui para a prática científica do pesquisador da educação. A oportunidade de diálogo com a pesquisa, de realizar exercícios de percepção e reflexão conjunta, proporciona aos participantes de um grupo de pesquisa um amadurecimento em relação ao caráter dialético da educação, que pela sua complexidade, não pode ser descaracterizada em sua dinamicidade. Nesse contexto, concebemos o pesquisador como protagonista, que deve saber lidar com o compromisso ético-político-social da atividade de pesquisa. Portanto, a nosso ver, a formação de pesquisadores demanda, não só o desenvolvimento de habilidades intelectuais requeridas pela prática profissional destes (seja como produtores de novos conhecimentos, como orientadores de pesquisa ou avaliadores de produção científica), mas também, e talvez o mais importante para nós aqui, como um sujeito/pesquisador capaz de se colocar no lugar do outro, de aprender com a crítica do outro, permitindo-se dar continuidade ao que já está posto e se dispondo a tentar melhorar aquilo que pode ser melhorado.

Por fim, sobre os trabalhos analisados, compreendemos que o fator de maior relevância é o reforço a respeito da importância de se explorar cada vez mais a formação de pesquisadores, em especial no contexto grupal, evidenciando quais fatores colaboram para que os sujeitos inseridos no processo de pesquisa desenvolvam a capacidade de tornarem-se pesquisadores multiplicadores e competentes. 


\section{REFERÊNCIAS}

BARDIN, Laurence. Análise de conteúdo. Lisboa: Edições 70, 1977.

CUNHA, Maria Isabel da. O professor universitário na transição de paradigmas. Araraquara: JM Editora, 1988.

FERRY, Gilles. Pedagogia de la formación. Buenos Aires: Centro de Publicaciones Educativas y Material Didáctico, 2004.

GARDNER, Susan. 'What's too much and what's too little?' The process of becoming an independent researcher. The Journal of Higher Education, v. 79, n. 3, p. 326-350, 2008.

KYEI-BLANKSON, Lydia. Training math and science teacher - researchers in a collaborative research environment: implications for math and science education. International Journal of Science and Mathematics Education. National Science Council, Taiwan, v.12, 2014.

OLIVEIRA, Valeska. Formação docente e dispositivo grupal: aprendizagens e significações imaginárias no espaço biográfico. Revista Educação, Porto Alegre, v. 34, n. 2, p. 180-188, maio/ago. 2011.

PIVETTA, Hedionéia. O grupo reflexivo como dispositivo de aprendizagem docente na educação superior. 2011. 213f. Tese (Doutorado em Educação) - Programa de PósGraduação em Educação, Universidade Federal de Santa Maria, Santa Maria, 2011.

; ISAIA, Sílvia. Grupo reflexivo de professores da educação superior: estudo sobre seus movimentos construtivos. Revista Portuguesa de Educação, Universidade do Minho: CIEd, v. 27, n. 1, p. 111-132. 2014.

ROMANOWSKI, Joana; ENS, Romilda. As pesquisas denominadas do tipo "estado da arte" em educação. Revista Diálogo Educ., Curitiba, v. 6, n.19, p. 37-50, set/dez. 2006.

ROMANOWSKI, Joana. As licenciaturas no Brasil: um balanço das teses e dissertações dos anos 90. 2002. 127f. Tese (Doutorado em Educação) - Programa de Pós-Graduação em Educação, Faculdade de Educação da Universidade de São Paulo, São Paulo, 2002.

ROSSETTO, Gislaine. Atividade de estudo e autonomia no processo de produção da pesquisa. 2013. 273f. Tese (Doutorado em Educação) - Programa de Pós-Graduação em Educação, Universidade Federal de Santa Maria, Santa Maria, 2013.

Constituição da autonomia no processo de produção da pesquisa na pós-graduação Stricto Sensu. Caderno Pesquisa, São Luís, v. 22, n. 1, jan/abr. 2015.

RYSER, Laura; MARKEY, Sean; HALSETH, Greg. Developing the next generation of community-based researchers: tips for undergraduate students, Journal of Geography in Higher Education, v. 37, n.1, p.11-27, 2013. 
SCOLA, Lourdes. Processo Grupal na Formação de Coordenadores de Grupo. 2012. 80f. Dissertação (Mestrado em Psicologia Social) - Faculdade de Psicologia da Pontifícia Universidade Católica do Rio Grande do Sul, Porto Alegre, 2012.

SINCLAIR, Jennifer; BARNACLE, Robyn; CUTHBERT, Denise. How the doctorate contributes to the formation of active researchers: what the research tells us, Studies in Higher Education, 2013. 